\title{
Systematic review of illness uncertainty management interventions for cancer patients and their family caregivers
}

\author{
Ting Guan ${ }^{1} \cdot$ Yousef Qan'ir ${ }^{2} \cdot$ Lixin Song ${ }^{2,3}$ (1) \\ Received: 8 July 2020 / Accepted: 2 December 2020 / Published online: 25 January 2021 \\ (C) The Author(s) 2021
}

\begin{abstract}
Purpose Illness uncertainty pervades individuals' experiences of cancer across the illness trajectory and is associated with poor psychological adjustment. This review systematically examined the characteristics and outcomes of interventions promoting illness uncertainty management among cancer patients and/or their family caregivers.

Methods PubMed, Scopus, PsycINFO, Cumulative Index to Nursing and Allied Health Literature (CINAHL), Embase, and Cochrane Database of Systematic Reviews were systematically searched for relevant literature. We included randomized controlled trials (RCTs) and quasi-experimental studies focusing on interventions for uncertainty management in cancer patients and/or their family caregivers. Results Our database searches yielded 26 studies. Twenty interventions were only offered to cancer patients, who were mostly elder, female, and White. All interventions included informational support. Other intervention components included emotional support, appraisal support, and instrumental support. Most interventions were delivered in person and via telephone $(n=8)$ or exclusively in person $(n=7)$. Overall, 18 studies identified positive intervention effects on illness uncertainty outcomes.

Conclusion This systematic review foregrounds the promising potential of several interventions - and especially multicomponent interventions - to promote uncertainty management among cancer patients and their family caregivers. To further improve these interventions' effectiveness and expand their potential impact, future uncertainty management interventions should be tested among more diverse populations using rigorous methodologies.
\end{abstract}

Keywords Cancer $\cdot$ Illness uncertainty $\cdot$ Intervention $\cdot$ Family caregiver $\cdot$ Systematic review $\cdot$ Social support

\section{Introduction}

Illness uncertainty is defined as "the inability of a person to determine the meaning of illness-related events" [1]. It can persist across the cancer trajectory from the time of diagnosis, through treatment, to long-term survivorship [2] and can be exacerbated by disease progression [3]. Illness uncertainty is widely recognized as a common and significant source of psychosocial stress among cancer patients [4], and studies have shown that increased uncertainty adversely affects

Lixin Song

1song@unc.edu

1 School of Social Work, University of North Carolina at Chapel Hill, Chapel Hill, NC, USA

2 School of Nursing, University of North Carolina at Chapel Hill, Chapel Hill, NC, USA

3 Lineberger Comprehensive Cancer Center, University of North Carolina at Chapel Hill, Chapel Hill, NC, USA cancer patients' psychological adjustment [5, 6], health behaviors [7], and quality of life [8,9]. This uncertainty can also extend to cancer patients' family caregivers. In fact, patients' partners have often reported higher levels of uncertainty compared to patients [3]. Research has also shown that increases in family caregivers' illness uncertainty are associated with poorer psychological adjustment to the diagnoses and progression of cancer in patients $[10,11]$. For example, uncertainty about the unknown outcomes of childhood cancers (e.g., late effects of cancer treatment, relapse) can increase parents' distress and dysfunctional behaviors [10].

To address the negative impacts of illness uncertainty on the health outcomes (e.g., quality of life) [12], researchers and practitioners have developed and implemented various interventions to help cancer patients and their family caregivers manage illness uncertainty. Three previous literature reviews have synthesized research developments related to uncertainty management interventions. In their review of interventions for managing uncertainty and fear of recurrence in female breast cancer survivors [13], Dawson and colleagues reported that the main intervention components included mindfulness, more effective 
patient-provider communication, and stress management through counseling [13]. In their integrative literature review of uncertainty among children with chronic illnesses and their families, Gunter and Duke concluded that the education and psychosocial support is important in reducing uncertainty [14]. In their recent meta-analysis of psychosocial uncertainty management interventions among adult patients with various diagnoses (e.g., cancer, HIV, heart disease) and their family caregivers [15], Zhang et al. reported that psychosocial interventions are effective in reducing short- and long-term uncertainty both among patients and their family caregivers [15].

The existing reviews have focused on patients with various types of chronic illnesses who may face different challenges from patients with cancer [16] or patients with a genderspecific type of cancer (e.g., breast cancer). It therefore remains unclear whether the findings of these reviews are generalizable to patients with other types of cancer. Additionally, although research has shown that children and adolescents with cancer are affected by illness uncertainty $[17,18]$, no systematic review has examined their experiences of uncertainty management interventions. Researchers and practitioners stand to benefit from a comprehensive review of the literature about illness uncertainty interventions for patients with different types of cancer across age groups and their family caregivers. To this end, our study (a) systematically reviews and synthesizes results of uncertainty management interventions for cancer patients and their family caregivers, (b) identifies the strengths and gaps in this line of research, and (c) suggests directions for future research. Specifically, our systematic review examines the characteristics of participants in studies of illness uncertainty management interventions as well as the characteristics and outcomes of those interventions.

\section{Methods}

We adapted a comprehensive systematic review protocol based on the Cochrane Collaboration and the Preferred Reporting Items for Systematic Reviews and Meta-Analyses (PRISMA) guidelines [19]. This protocol was registered with PROSPERO, an international prospective register of systematic reviews, prior to the beginning of the study (registration number CRD42019128004).

\section{Eligibility criteria}

We used the population, interventions, comparator, outcomes, and study (PICOS) design(s) to guide our inclusion criteria [20]. Studies eligible for inclusion are as follows: (a) targeted cancer patients and/or their family caregivers; (b) included uncertainty management in their research aims and/or as a part of the intervention's contents; (c) reported intervention effects on illness uncertainty; (d) used randomized controlled trials (RCTs) or quasi-experimental designs; and (e) were published in English between January 1, 2000 and December 31, 2019. The search was not limited to studies using a control or comparison group.

\section{Search methods}

A university health sciences librarian helped to develop the search terms and identify relevant search databases. We conducted electronic literature searches using six databases: PubMed, Scopus, PsycINFO, Cumulative Index to Nursing and Allied Health Literature (CINAHL), Embase, and Cochrane Database of Systematic Reviews. The database searches used Boolean terms "OR" and "AND" with combinations of the following search terms: (uncertainty) AND (cancer OR neoplasm*OR tumor OR myeloma OR oncolog*) AND (intervention OR program OR effect OR effectiveness OR treatment OR therapy) AND (patient OR patients OR caregiv* OR family OR families) AND (psych* OR mental* OR emotion*).

To identify studies potentially overlooked by our electronic searches, our research team conducted forward and backward citation chaining and hand searched Web of Science, Google Scholar, and prominent journals in the field to identify relevant articles for inclusion. Two coauthors independently reviewed the titles and abstracts and then-if an article merited further consideration-its full text using Covidence. Covidence is a web-based software platform designed to support the efficient production of systematic reviews [21]. We resolved any discrepancies in the two coauthors' respective decisions regarding articles' inclusion via group discussion among all team members.

\section{Assessment of risk of bias in the included studies}

We used the Cochrane Collaboration's Risk of Bias Tool [22] to assess various sources of bias: selection bias, performance bias, detection bias, attrition bias, reporting bias, and other possible sources of bias (Appendix). Each domain was endorsed with a rating of "low risk," "high risk," or "unclear risk" following guideline's criteria. Two coauthors independently conducted all risk of bias assessments, and we resolved any differences in their assessments through team discussion.

\section{Data extraction and synthesis}

Two of the coauthors independently extracted relevant data from the studies that met our inclusion criteria. We compared these extracted results and resolved any discrepancies through team discussion before merging the data. Because the included studies displayed different participant characteristics, intervention components, outcomes, and follow-up periods, we could not conduct a meta-analysis of their findings. We summarized the narratives and themes of each study and its results. Guided by House's conceptualization of social support [23], we classified each intervention's 
components into four categories: informational support, emotional support, appraisal support, and instrumental support.

\section{Results}

As shown in Fig. 1, our initial search of electronic databases and records and our hand searches of other sources yielded 1156 records. After removing duplicates, we identified 681 articles for title and abstract review, of which 49 were retained for a full-text review. After removing the studies that did not meet the inclusion criteria, we included 26 articles in this review.

\section{Characteristics of studies}

The majority of studies were conducted in the USA $(n=16)$. Others were conducted in Canada, China, Japan, United Kingdom (UK), and Vietnam. Eighteen studies were RCTs; one study used a RCT crossover design [24]. Eight studies were quasi-experimental studies (i.e., five "1-group pretest-posttest" studies, two "2-group pretest-posttest" studies, and one "2-group posttest" study) (Table 1). Among the 20 studies that included a control group, 12 studies used usual care, and eight included an active control group (e.g., a self-help group [25]; groups receiving recorded and written messages [26], telephone calls [27], and delayed interventions [28]). Sample sizes of included studies ranged from 9 [29] to 968 participants [30]. Among all studies, only seven studies were guided by theoretical frameworks such as the stress and coping theory $(n=5)[30-34]$, the uncertainty in illness theory $(n=1)$ [29], the double ABCX model $(n=1)$ [34], and the resilience model $(n=1)$ [35].

\section{Characteristics of participants}

Twenty interventions were only offered to cancer patients. Two studies targeted family caregivers (i.e., the parents of children with

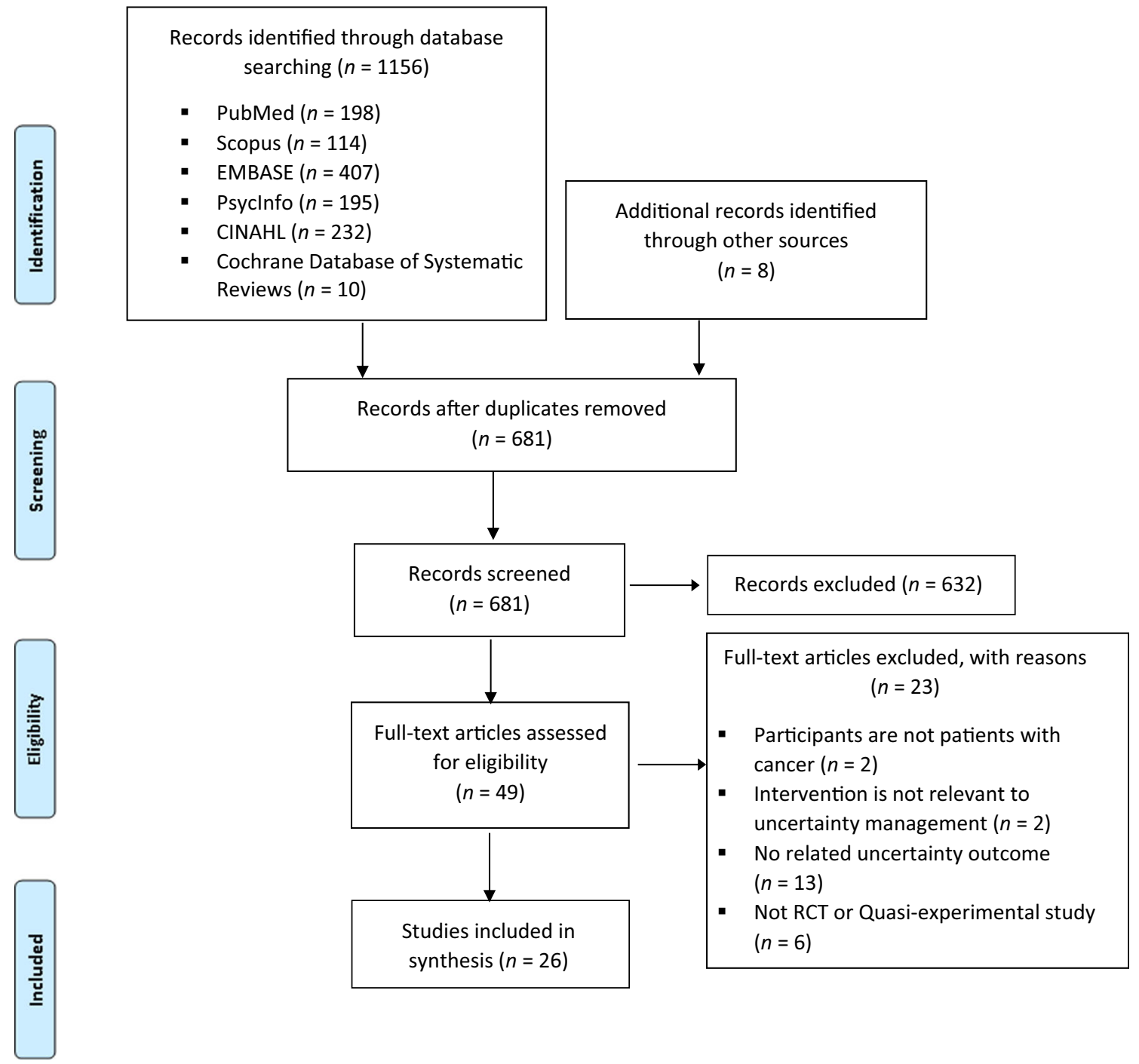

Fig. 1 PRISMA flow diagram 


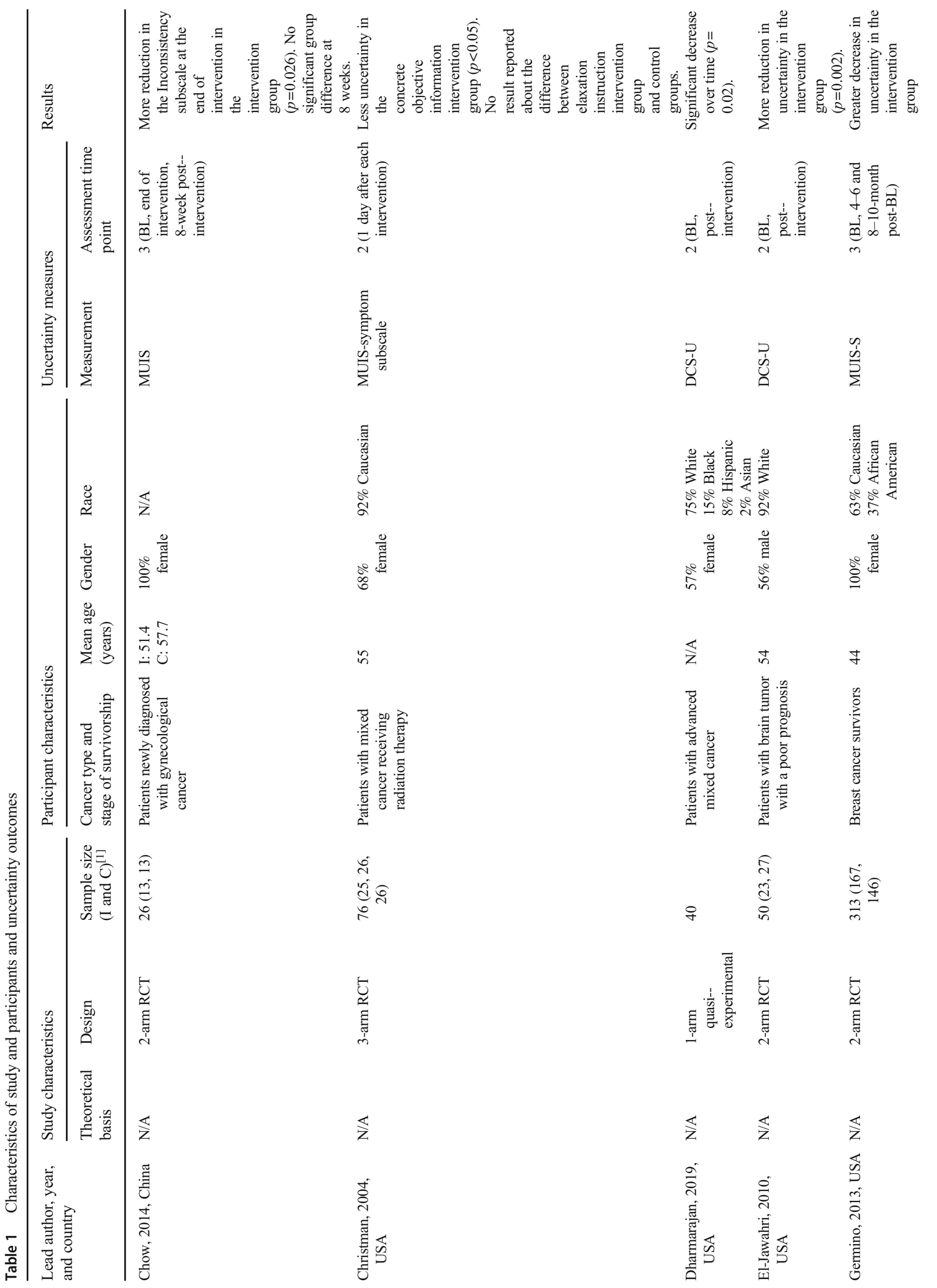




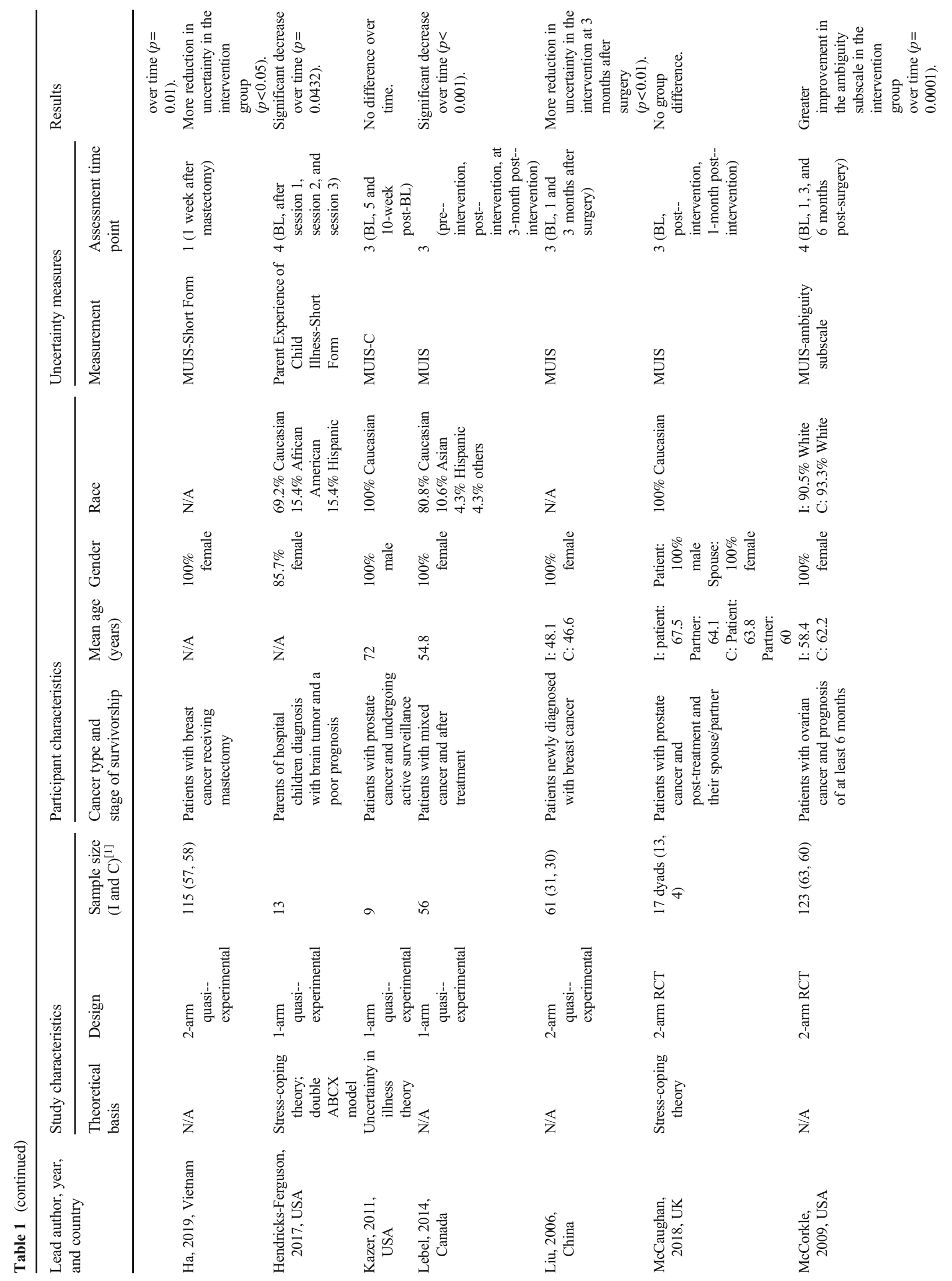




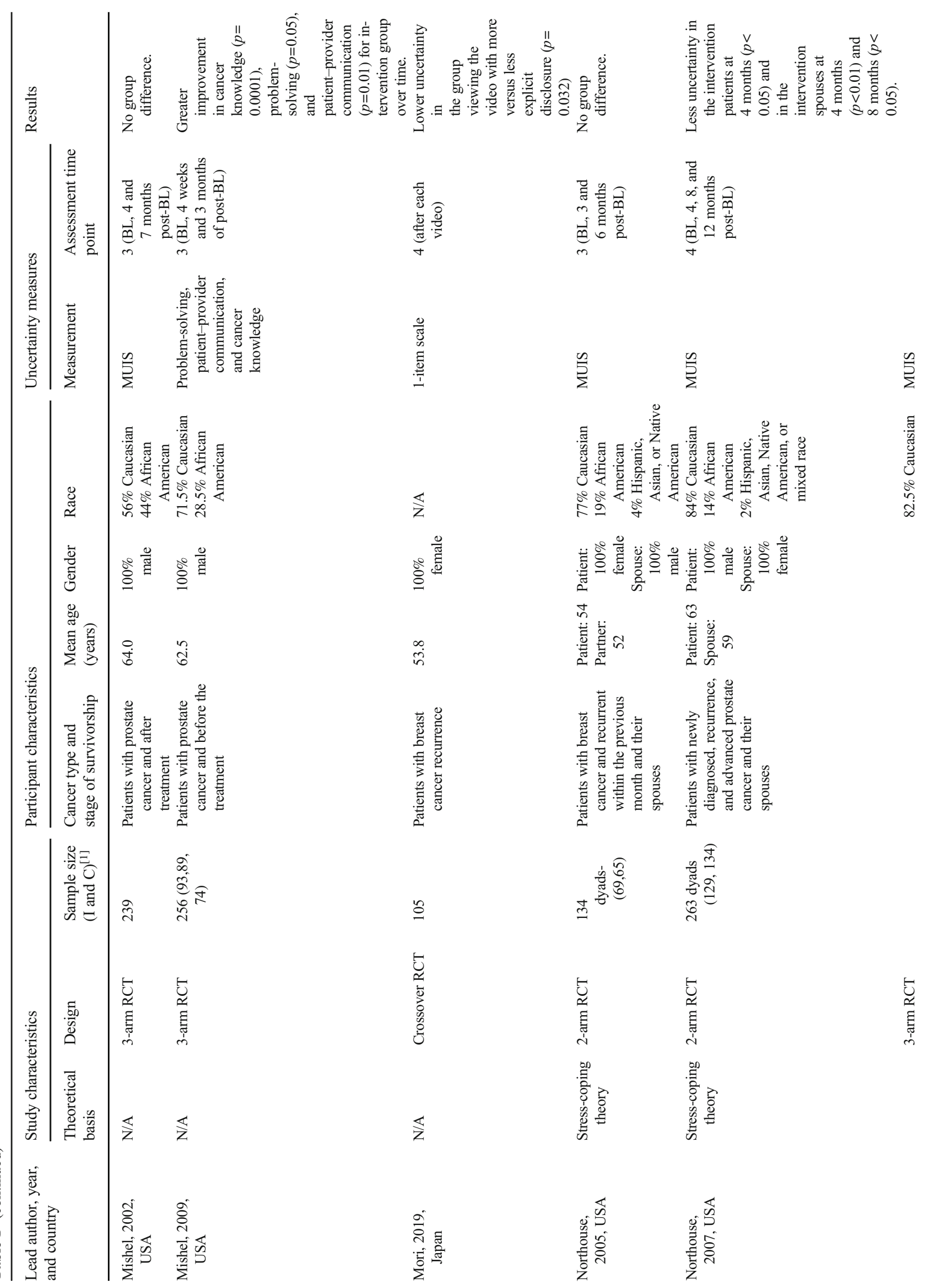




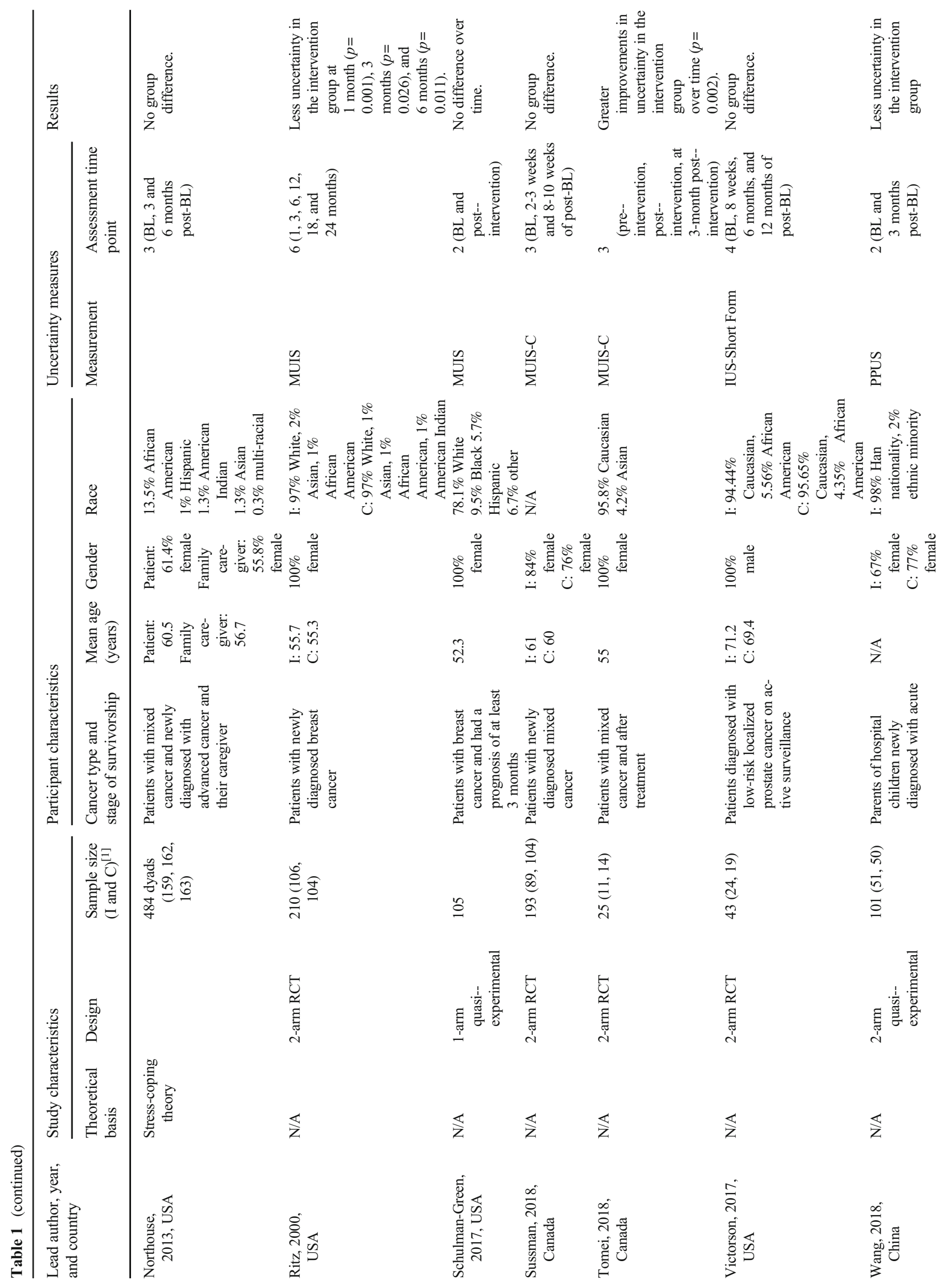




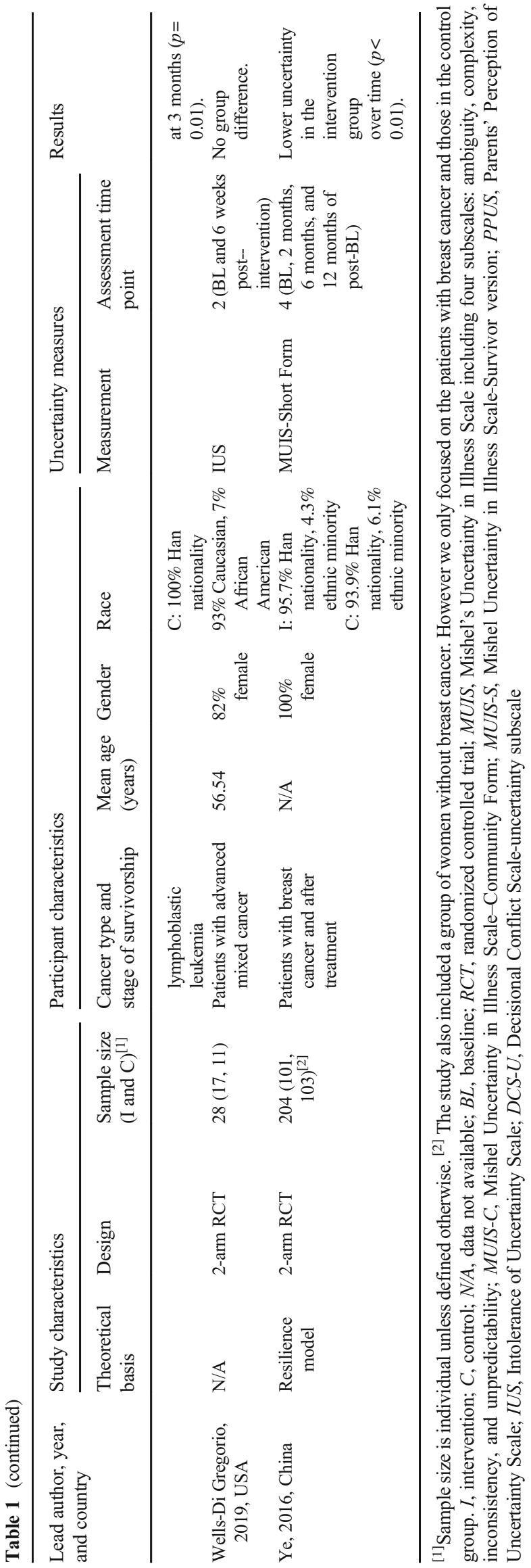

cancer) $[34,36]$. Four interventions were offered to both cancer patients and their partners and/or family caregivers [30-33].

Participants were recruited from hospitals, by invitation from a care provider, or via mailing and poster initiatives. The majority of studies recruited homogeneous patient populations, including patients with breast cancer $(n=8)$, prostate cancer $(n=6)$, brain tumor $(n=2)$, leukemia $(n=1)$, gynecological cancer $(n=1)$, and ovarian cancer $(n=1)$. Approximately $26.9 \%$ of studies $(n=7)$ targeted patients with various types of cancer. Regarding the stages of the cancer trajectory, these studies focused on cancer patients who were post-treatment $(n=8)$; patients with newly diagnosed cancer $(n=6)$; patients with advanced cancer $(n=5)$; patients undergoing active surveillance for cancer $(n=2)$; patients receiving treatment $(n=2)$; patients in recurrence $(n=2)$; and/or patients at a mix of stages $(n=1)$. With only two studies targeting parents of children and adolescents with cancer, the majority of the studies have focused on participants who were mostly female and White, and with an average age ranged from 44 to 72 years.

\section{Intervention characteristics}

Table 2 summarizes the interventions' characteristics. Nineteen studies $(73.1 \%)$ included uncertainty management as their main aim.

Theoretical basis Twelve studies (46\%) described the theoretic frameworks used to guide different interventions. Five interventions were developed based on Mishel's uncertainty in illness theory [27, 37-40]. Other theoretical models that guided the development of illness uncertainty management interventions also included the thematic counseling model [25], self-regulation theory [26], Leventhal's common sense model [37], Brooten's cost-quality model [41], self and family management framework [42], theory of self-efficacy, theory of stress and coping [31], cognitive behavioral therapy and acceptance and commitment therapy [43], and mindfulnessbased stress reduction [44].

Contents and components All of the interventions in our sampled studies included informational support that provided knowledge and resources related to illness, treatment, procedures, and symptom management. Eleven studies included emotional and psychological support from interventionist and peer groups. Nine studies included appraisal support that provided information and skills training for self-evaluation and positive perception, such as cognitive reframe and restructuring. Five studies included instrumental support that helped improve participants' care coordination and ability to manage resources, referrals (social services, mental health, physical therapy), and continual follow-up schedules. Sixteen studies included two or more types of intervention components. 


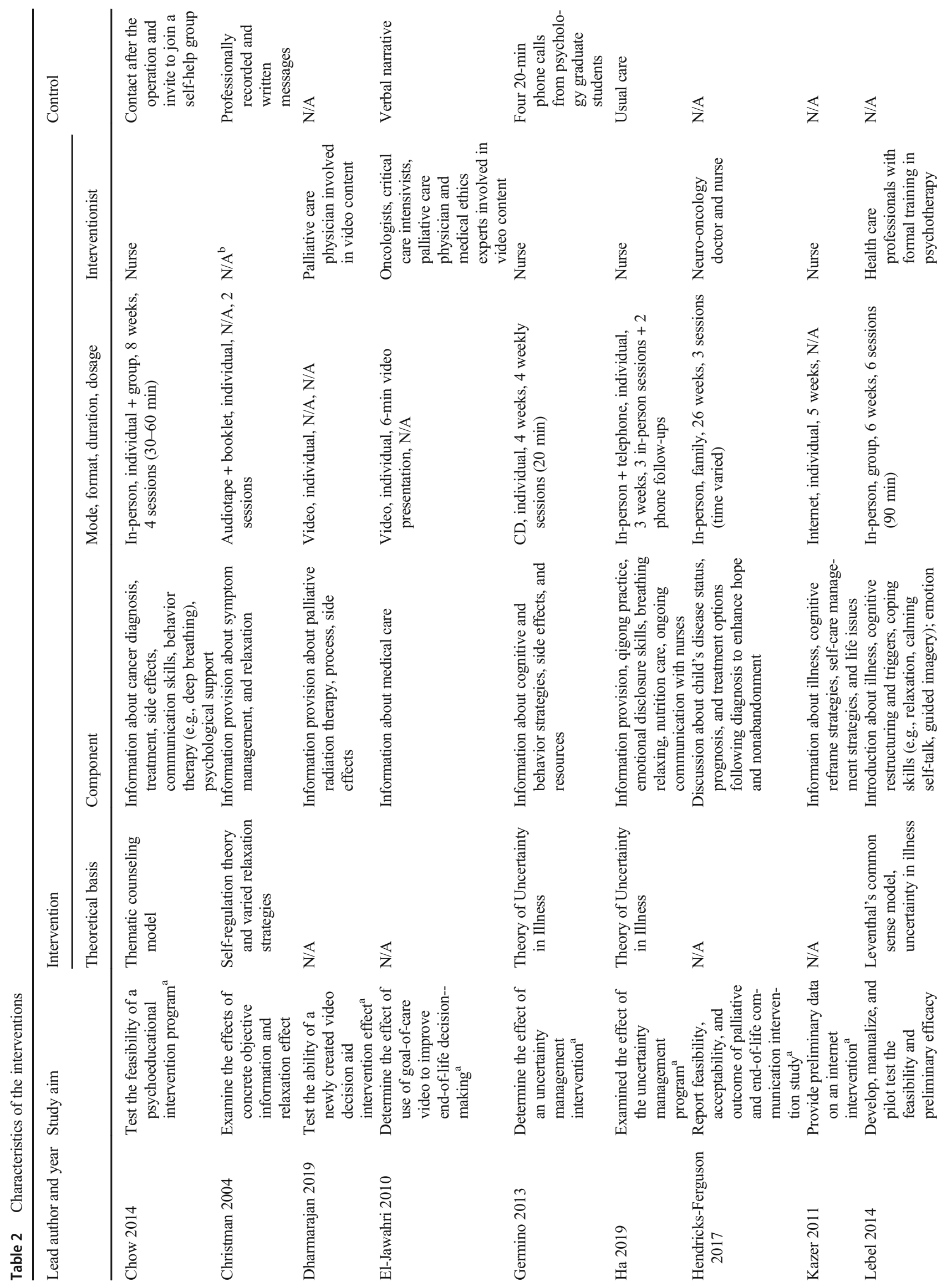




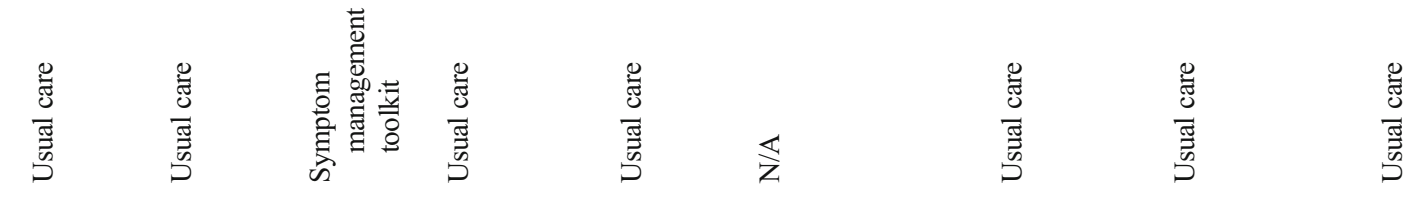

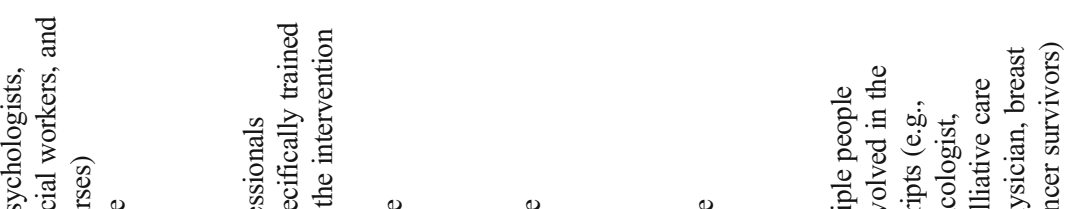

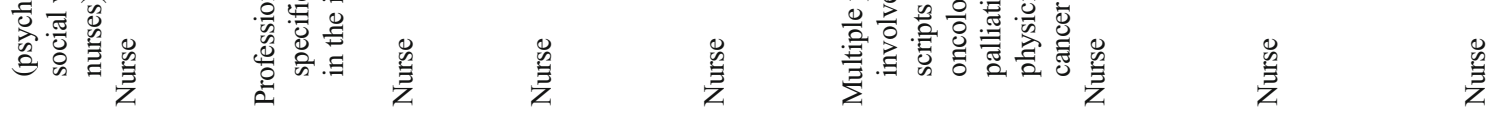

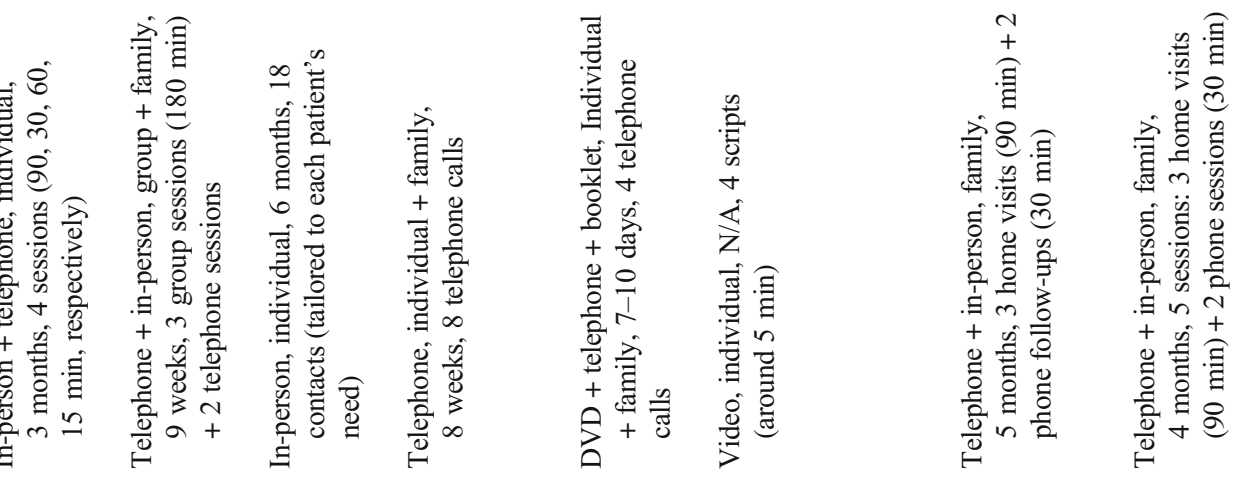

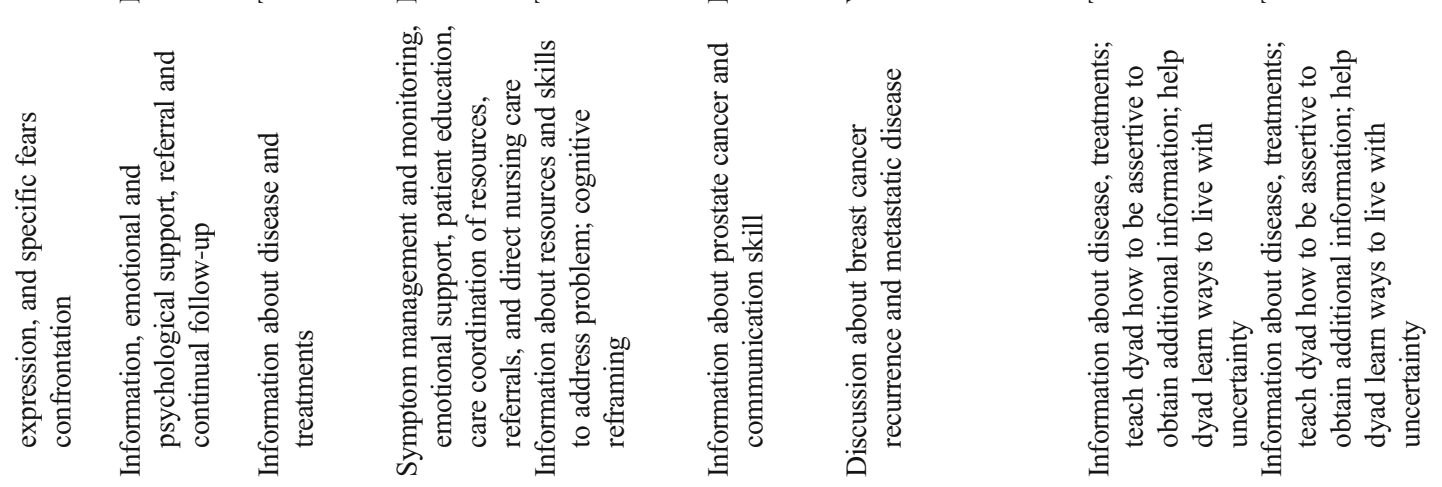<smiles>C[C@H]1[C@H]2C[C@@H](C)[C@H]1C2</smiles>

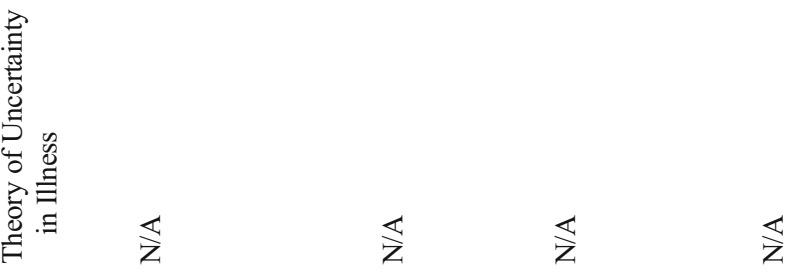

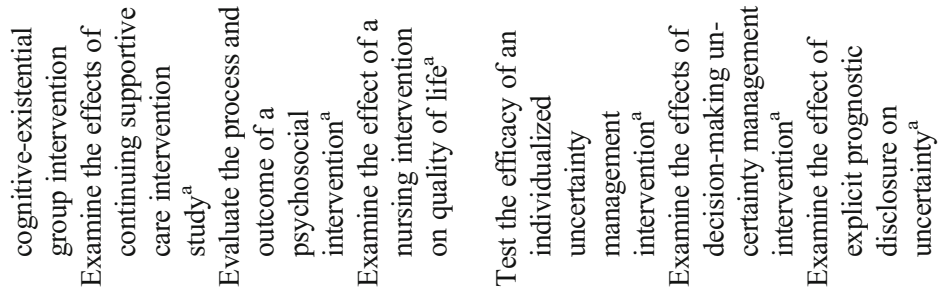

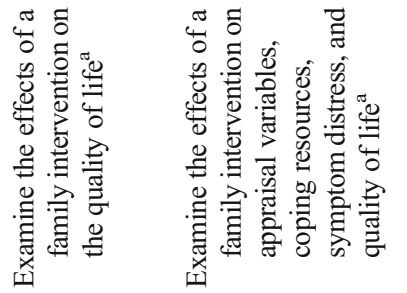

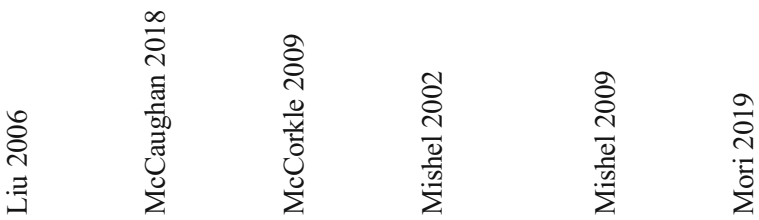

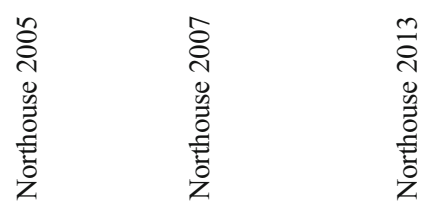




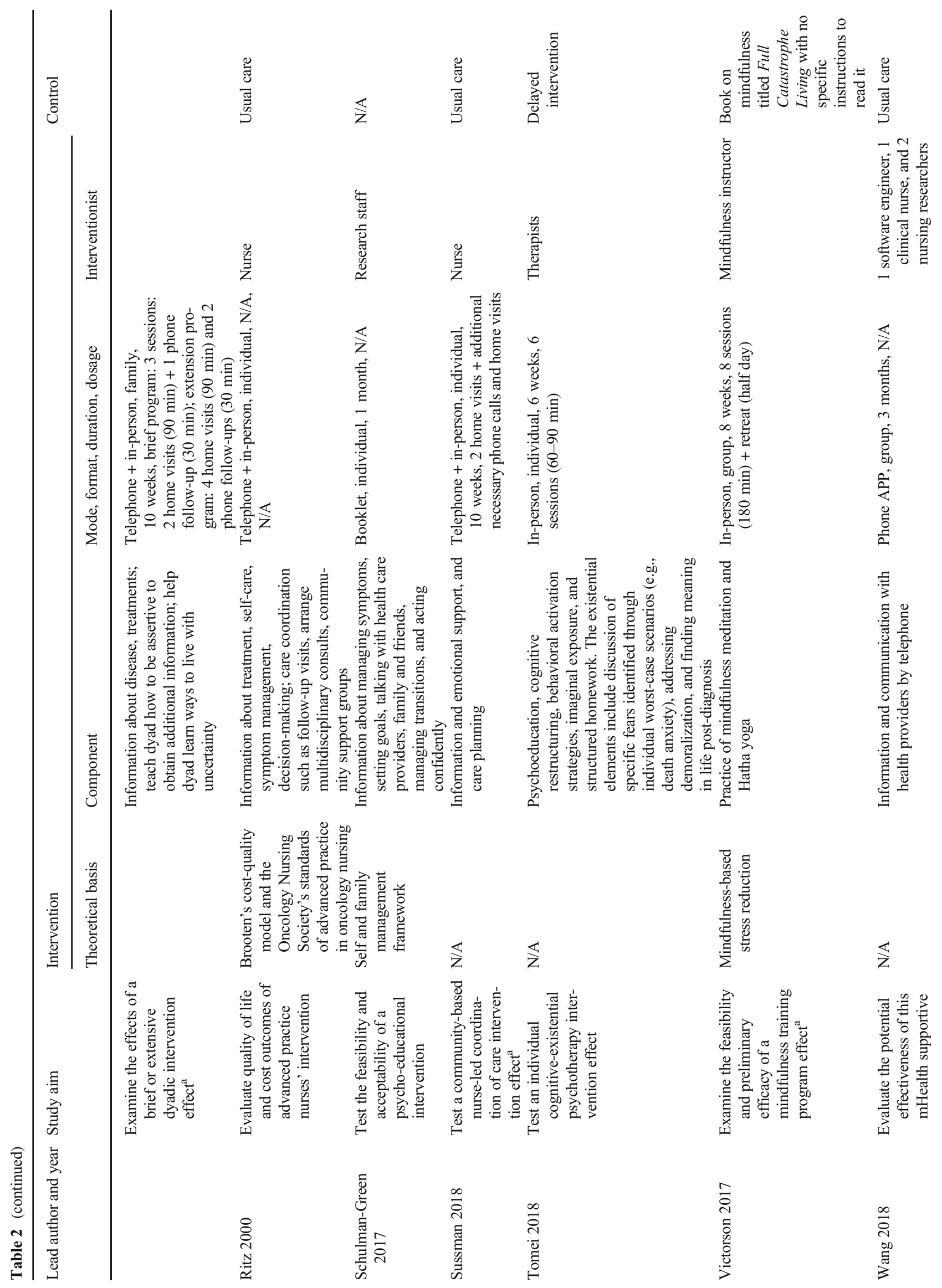




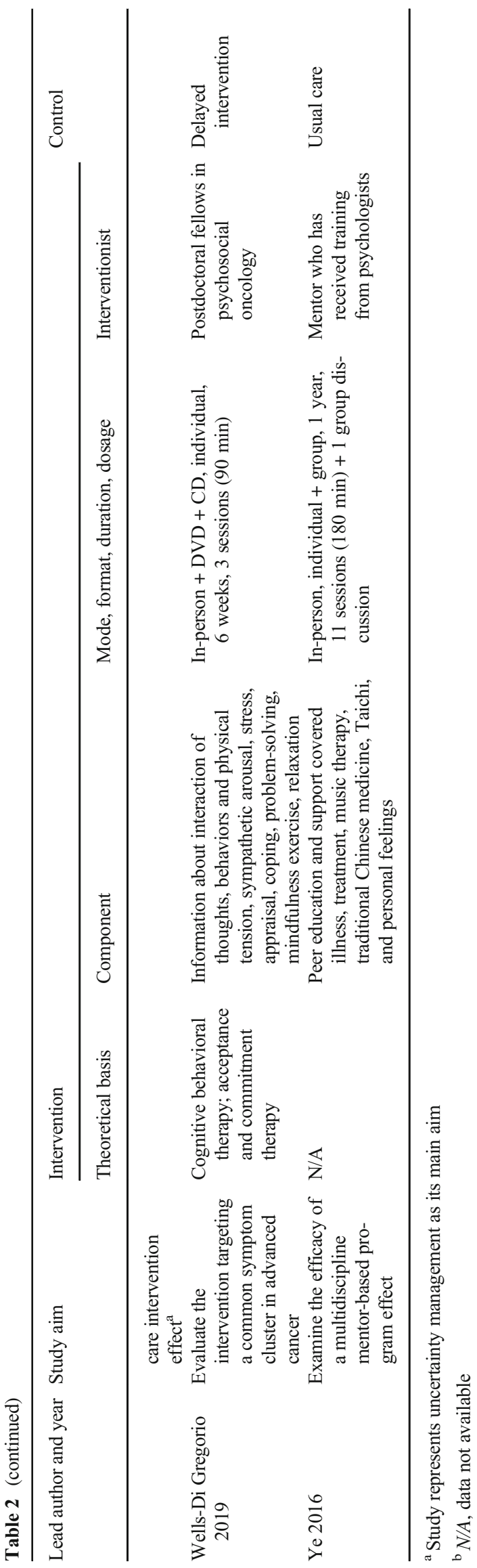

Mode of delivery, format, duration, and dosage The studied interventions employed a variety of delivery modes. The majority of these interventions used both in-person and telephone delivery $(n=8)$ or in-person delivery $(n=7)$. The remaining eleven interventions used other delivery mechanisms including CD [27], DVDs [45, 46], telephone calls [38], informational booklets [42], internet [29], phone apps [36], or a combination of in-person delivery with DVD and CD content [43]. Most interventions were delivered to participants individually $(n=14)$, in a group format $(n=3)[36,37,44]$, or in family format $(n=4)$ [30, 32-34]. Other interventions used a combination of individual and group $(n=2)[25,35]$, individual and family $(n=2)[38,39]$, or group and family $(n=1)$ [31] delivery methods. The duration and dosage of the uncertainty management interventions varied across studies, ranging from one session [46] to 1-year period [35].

Interventionist In thirteen studies, nurses delivered the interventions. Five interventions were delivered by professionals who had counseling or psychosocial background and training [28, 31, 35, 43, 44]. Five interventions were designed or delivered by multidisciplinary professionals $[24,34,36,37$, 46]. One intervention was delivered by research staff [42] and one intervention design involved physicians [47]. One study did not report on the professional background of the interventionists [26].

\section{Intervention outcome}

Illness uncertainty assessment The scale most commonly used to measure an intervention's effect on uncertainty was the Mishel Uncertainty in Illness Scale (MUIS) $(n=$ 19). This scale has different versions including MUISCommunity version [48], MUIS-Survivor version [27], MUIS-Short version [40], and Parents' Perception of Uncertainty [36], which is based on the MUIS and measures parents' uncertainty. Other studies measured uncertainty using the symptom and ambiguity subscale of MUIS [26, 49], the Decisional Conflict Scale-uncertainty subscale [46, 47], Parent Experience of Child Illness-Short Form [34], and the Intolerance of Uncertainty Scale [43, 44]. One study measured uncertainty using a 1-item scale [24]. One study measured uncertainty using three proxy measures (i.e., problem-solving, patient-provider communication, and cancer knowledge) [39]. Most studies assessed illness uncertainty outcomes using a longitudinal design with two time points $(n=6)$; three time points $(n=12)$; four time points $(n=6)$; or six time points $(n=1)$ [41].

Illness uncertainty outcomes Overall, $65 \%$ of studies $(n=17)$ suggested that an illness uncertainty management intervention had a positive effect on uncertainty outcomes. Out of the eighteen RCTs, eleven studies demonstrated that the 
participants in the intervention group reported significant less uncertainty than those in the control group at follow-ups. Of these studies, eight studies assessed outcomes at multiple time points. Five studies reported more reduction in uncertainty in the intervention group over time [27, 28, 35, 39, 49]. Among eight quasi-experimental studies, three studies with a control group found that participants in the intervention groups reported significantly less uncertainty compared to those in the control group [36, 40, 45]. Among five quasi-experimental studies without a control group, three studies showed that intervention participants reported a significant decrease in uncertainty over time $[34,37,46]$.

\section{Risk of bias assessment}

We evaluated each study's risk of bias using the Cochrane Collaboration's Risk of Bias Tool (Table 3). The eighteen RCTs had unclear $(n=11)$, high $(n=2)$, or low $(n=5)$ risk of bias. Most trials were classified as having unclear risk of bias because they did not describe the method used to generate the allocation sequence or report any strategies to maintain intervention fidelity (e.g., consistent intervention use among participants). We found that six quasiexperimental studies had high risk of bias. Most quasiexperimental studies used one-group pre- and post-designs without a control group; therefore, they had high risk of bias in random sequence generation and baseline imbalance.

\section{Discussion}

This study systematically reviewed the characteristics and outcomes of illness uncertainty management-related interventions for adult and childhood cancer patients as well as their

Table 3 Assessment of study quality based on published data using Cochrane Collaboration's criteria

\begin{tabular}{|c|c|c|c|c|c|c|c|c|c|}
\hline Lead author and year & $\begin{array}{l}\text { Random } \\
\text { sequence } \\
\text { generation }\end{array}$ & $\begin{array}{l}\text { Allocation } \\
\text { concealment }\end{array}$ & $\begin{array}{l}\text { Blinding of } \\
\text { participants and } \\
\text { personnel }\end{array}$ & $\begin{array}{l}\text { Blinding of } \\
\text { outcome } \\
\text { assessment }\end{array}$ & $\begin{array}{l}\text { Incomplete } \\
\text { outcome } \\
\text { data }\end{array}$ & $\begin{array}{l}\text { Selective } \\
\text { reporting }\end{array}$ & $\begin{array}{l}\text { Deferential } \\
\text { intervention } \\
\text { use }\end{array}$ & $\begin{array}{l}\text { Baseline } \\
\text { imbalance }\end{array}$ & $\begin{array}{l}\text { Level } \\
\text { of risk }\end{array}$ \\
\hline Chow 2014 & $\mathrm{~L}$ & $\mathrm{~L}$ & $\mathrm{~L}$ & $\mathrm{~L}$ & $\mathrm{~L}$ & $\mathrm{~L}$ & $\mathrm{H}$ & $\mathrm{L}$ & $\mathrm{H}$ \\
\hline Christman 2004 & $\mathrm{U}$ & $\mathrm{L}$ & $\mathrm{L}$ & $\mathrm{L}$ & $\mathrm{L}$ & $\mathrm{L}$ & $\mathrm{U}$ & $\mathrm{L}$ & $\mathrm{U}$ \\
\hline Dharmarajan 2019 & $\mathrm{H}$ & $\mathrm{U}$ & $\mathrm{L}$ & $\mathrm{L}$ & $\mathrm{L}$ & $\mathrm{L}$ & $\mathrm{L}$ & $\mathrm{H}$ & $\mathrm{H}$ \\
\hline El-Jawahri 2010 & $\mathrm{U}$ & $\mathrm{L}$ & $\mathrm{L}$ & $\mathrm{L}$ & $\mathrm{L}$ & $\mathrm{L}$ & $\mathrm{U}$ & $\mathrm{L}$ & $\mathrm{U}$ \\
\hline Germino 2013 & $\mathrm{~L}$ & $\mathrm{~L}$ & $\mathrm{~L}$ & $\mathrm{~L}$ & $\mathrm{~L}$ & $\mathrm{~L}$ & $\mathrm{U}$ & $\mathrm{L}$ & $\mathrm{L}$ \\
\hline На 2019 & $\mathrm{H}$ & $\mathrm{L}$ & $\mathrm{L}$ & $\mathrm{L}$ & $\mathrm{L}$ & $\mathrm{L}$ & $\mathrm{U}$ & $\mathrm{L}$ & $\mathrm{H}$ \\
\hline $\begin{array}{l}\text { Hendricks-Ferguson } \\
2017\end{array}$ & $\mathrm{H}$ & $\mathrm{U}$ & $\mathrm{L}$ & $\mathrm{L}$ & $\mathrm{L}$ & $\mathrm{L}$ & $\mathrm{U}$ & $\mathrm{H}$ & $\mathrm{H}$ \\
\hline Kazer 2011 & $\mathrm{H}$ & $\mathrm{U}$ & $\mathrm{L}$ & $\mathrm{L}$ & $\mathrm{H}$ & $\mathrm{L}$ & $\mathrm{U}$ & $\mathrm{H}$ & $\mathrm{H}$ \\
\hline Lebel 2014 & $\mathrm{H}$ & $\mathrm{U}$ & $\mathrm{L}$ & $\mathrm{L}$ & $\mathrm{L}$ & $\mathrm{L}$ & $\mathrm{U}$ & $\mathrm{H}$ & $\mathrm{H}$ \\
\hline Liu 2006 & $\mathrm{H}$ & $\mathrm{U}$ & $\mathrm{L}$ & $\mathrm{L}$ & $\mathrm{L}$ & $\mathrm{L}$ & $\mathrm{U}$ & $\mathrm{H}$ & $\mathrm{H}$ \\
\hline McCaughan 2018 & $\mathrm{U}$ & $\mathrm{L}$ & $\mathrm{L}$ & $\mathrm{L}$ & $\mathrm{L}$ & $\mathrm{L}$ & $\mathrm{H}$ & $\mathrm{L}$ & $\mathrm{H}$ \\
\hline McCorkle 2009 & $\mathrm{U}$ & $\mathrm{L}$ & $\mathrm{L}$ & $\mathrm{L}$ & $\mathrm{L}$ & $\mathrm{L}$ & $\mathrm{U}$ & $\mathrm{L}$ & $\mathrm{U}$ \\
\hline Mishel 2002 & $\mathrm{U}$ & $\mathrm{L}$ & $\mathrm{L}$ & $\mathrm{L}$ & $\mathrm{L}$ & $\mathrm{L}$ & $\mathrm{U}$ & $\mathrm{L}$ & $\mathrm{U}$ \\
\hline Mishel 2009 & $\mathrm{U}$ & $\mathrm{L}$ & $\mathrm{L}$ & $\mathrm{L}$ & $\mathrm{L}$ & $\mathrm{L}$ & $\mathrm{U}$ & $\mathrm{L}$ & $\mathrm{U}$ \\
\hline Mori 2019 & $\mathrm{~L}$ & $\mathrm{~L}$ & $\mathrm{~L}$ & $\mathrm{~L}$ & $\mathrm{~L}$ & $\mathrm{~L}$ & $\mathrm{~L}$ & $\mathrm{~L}$ & $\mathrm{~L}$ \\
\hline Northouse 2005 & $\mathrm{U}$ & $\mathrm{L}$ & $\mathrm{L}$ & $\mathrm{L}$ & $\mathrm{L}$ & $\mathrm{L}$ & $\mathrm{U}$ & $\mathrm{L}$ & $\mathrm{U}$ \\
\hline Northouse 2007 & $\mathrm{U}$ & $\mathrm{L}$ & $\mathrm{L}$ & $\mathrm{L}$ & $\mathrm{L}$ & $\mathrm{L}$ & $\mathrm{U}$ & $\mathrm{L}$ & $\mathrm{U}$ \\
\hline Northouse 2013 & $\mathrm{U}$ & $\mathrm{L}$ & $\mathrm{L}$ & $\mathrm{L}$ & $\mathrm{L}$ & $\mathrm{L}$ & $\mathrm{U}$ & $\mathrm{L}$ & $\mathrm{U}$ \\
\hline Ritz 2000 & $\mathrm{U}$ & $\mathrm{L}$ & $\mathrm{L}$ & $\mathrm{L}$ & $\mathrm{L}$ & $\mathrm{L}$ & $\mathrm{U}$ & $\mathrm{L}$ & $\mathrm{U}$ \\
\hline $\begin{array}{l}\text { Schulman-Green } \\
2017\end{array}$ & $\mathrm{H}$ & $\mathrm{U}$ & $\mathrm{L}$ & $\mathrm{L}$ & $\mathrm{L}$ & $\mathrm{L}$ & $\mathrm{U}$ & $\mathrm{H}$ & $\mathrm{H}$ \\
\hline Sussman 2018 & $\mathrm{~L}$ & $\mathrm{~L}$ & $\mathrm{~L}$ & $\mathrm{~L}$ & $\mathrm{~L}$ & $\mathrm{~L}$ & $\mathrm{U}$ & $\mathrm{L}$ & $\mathrm{L}$ \\
\hline Tomei 2018 & $\mathrm{~L}$ & $\mathrm{~L}$ & $\mathrm{~L}$ & $\mathrm{~L}$ & $\mathrm{~L}$ & $\mathrm{~L}$ & $\mathrm{U}$ & $\mathrm{L}$ & $\mathrm{L}$ \\
\hline Victorson 2017 & $\mathrm{~L}$ & $\mathrm{~L}$ & $\mathrm{~L}$ & $\mathrm{~L}$ & $\mathrm{U}$ & $\mathrm{L}$ & $\mathrm{U}$ & $\mathrm{L}$ & $\mathrm{U}$ \\
\hline Wang 2018 & $\mathrm{H}$ & $\mathrm{U}$ & $\mathrm{L}$ & $\mathrm{L}$ & $\mathrm{L}$ & $\mathrm{L}$ & $\mathrm{U}$ & $\mathrm{H}$ & $\mathrm{H}$ \\
\hline $\begin{array}{l}\text { Wells-Di Gregorio } \\
2019\end{array}$ & $\mathrm{~L}$ & $\mathrm{~L}$ & $\mathrm{~L}$ & $\mathrm{~L}$ & $\mathrm{~L}$ & $\mathrm{~L}$ & $\mathrm{~L}$ & $\mathrm{~L}$ & $\mathrm{~L}$ \\
\hline Ye 2016 & $\mathrm{U}$ & $\mathrm{U}$ & $\mathrm{L}$ & $\mathrm{L}$ & $\mathrm{L}$ & $\mathrm{L}$ & $\mathrm{L}$ & $\mathrm{L}$ & $\mathrm{U}$ \\
\hline
\end{tabular}

$L$, low risk; $H$, high risk; $U$, unclear 
family caregivers. We found that all interventions evaluated in the included studies provided informational support. Other intervention components included emotional support, appraisal support, and instrumental support. The majority of studies used both in-person and telephone or in-person intervention delivery modes. The majority of studies suggested positive effects of illness uncertainty management-related interventions on uncertainty outcomes. With only two studies focused on parents of children and adolescents with cancer, the majority of interventions were only offered to cancer patients, who were mostly older adults, female, and White.

Overall, the majority of studies $(65 \%)$ found that illness uncertainty management-related interventions had positive effects on uncertainty outcomes. Multi-component interventions, which used integrated resources to target multiple aspects of illness uncertainty such as informational support and emotional support, appear to be the most effective in managing illness uncertainty in cancer patients and their family caregivers. For example, Lebel et al. found that one intervention proved effective when employing a combination of introductory material about illness, cognitive restructuring and triggers, coping skills (e.g., relaxation, calming self-talk, guided imagery), and practice expressing emotion and confronting specific fears [37]. However, the positive effects of only a few interventions appeared to endure over time, possibly indicating that many interventions' duration should be extended or include booster sessions as needed [38].

In general, we found that uncertainty management interventions were comprised of a variety of components including informational, emotional, appraisal, and instrumental support. Informational support is the key to helping cancer patients and their family caregivers manage uncertainty. Our findings corroborate those of two previous literature reviews of psychosocial interventions for managing uncertainty in childhood cancer patients and adult patients with different chronic illnesses [14, 15]. Findings from these reviews may also collectively indicate that individualized educational interventions provide information that empowers patients to successfully develop positive coping mechanisms. These findings are consistent with core tenets of Mishel's uncertainty in illness theory, which posits that uncertainty occurs when patients lack the information or knowledge needed to fully interpret an illness and its treatment [1]. Informational support can enlarge patients' information and knowledge base, enabling them to better understand an illness and thus experience less uncertainty. Moreover, when uncertainty occurs, it can be difficult for patients to form a cognitive structure [1]. Appraisal supports such as cognitive reframing can help patients reinterpret their illness and view a traumatic event as manageable [38]. Emotional and instrumental support can also provide patients with psychosocial resources to manage their uncertainty.

Most interventions were delivered using either inperson and telephone or in-person formats. This finding contrasts with Zhang et al.'s systematic review and metaanalysis of patients with chronic illnesses, which identified written educational materials as the most frequently used mode of intervention delivery [15]. Given the complexity of information provision and cancer patients' potential for psychosocial distress, in-person meetings may be the preferred mode of intervention delivery. A format combining in-person and follow-up telephone components can both evaluate patients' current understandings of their illness and help them reassess their emotional responses [27]. Our systematic review found limited evidence of the effectiveness of technology-based (e.g., web-based, apps) uncertainty management interventions $[29,36]$. This area of research is still emerging, as indicated by the recent publication dates of studies of these technology-based interventions, their pilot and feasibility research aims, and their use of small sample sizes. Given these interventions' potential ability to provide cost-effective psychosocial services [50] to manage uncertainty across the cancer care continuum, researchers should develop and evaluate technology-based interventions for uncertainty management using a rigorous research design (e.g., RCT) with a sufficiently powered sample.

Notably, only four interventions were offered jointly to cancer patients and their spouses or partners, and only one of these reported significant improvement in the uncertainty outcome among cancer patients and their spouses [33]. This comparatively low number perhaps reflects the challenges to conducting family-based research, such as explaining the purpose of the research to multiple participants, having an extended recruitment phase that involves contacting and obtaining consent from more people, and high refusal rates $[31,51]$. The small number of interventions that included spouses or partners is striking, as family caregivers play key roles in supporting cancer patients [52] and often experience higher levels of uncertainty than patients [3]. Interventions delivered to patients' family caregivers can improve their knowledge, coping skills, and quality of life [53], which will in turn improve cancer patients' care and outcomes (e.g., quality of life) given the synergetic interdependent relationships between cancer patients and their family caregivers [54]. There is a pressing need for future research to inform the development of interventions designed to manage uncertainty for both cancer patients and their caregivers.

Our review also indicates that future research must diversify the age, gender, and racial distributions of sample 
populations used to evaluate the outcomes of illness uncertainty interventions. Although previous research has shown that uncertainty is a common experience for children and adolescents with cancer [14], we identified only two interventions that assisted the parents of children with cancer to manage uncertainty $[34,36]$, and no intervention in our sample targeted children and adolescents with cancer. Therefore, because experiences of uncertainty can vary across different age groups or developmental stages [55], researchers should develop age-appropriate interventions that take into account the specific needs of children and adolescents with cancer. Furthermore, most of the participants in the intervention studies in this review were female, White, and older adult cancer patients. Future research regarding illness uncertainty management interventions should create strategies to increase the number of male patients and family caregivers in intervention programming. Although recruiting men for clinical trials is difficult because men are often reluctant to access services and to recognize that they need help [31], male cancer patients (e.g., prostate cancer) often experience uncertainty about their treatment decision-making and/or their management of cancer treatment-related symptoms and side effects [3, 56]. Finally, although two interventions succeed to include a sufficient number of African American cancer patients $[27,38]$, the majority of the study populations were White. Given that one study found that African American cancer patients reported higher levels of uncertainty than White cancer patients [3], future intervention should be tailored to help patients from minority groups and researchers should gather data about the effects of interventions using more diverse samples of cancer patients and their family caregivers.

According to the Cochrane Collaboration's Risk of Bias Tool, most studies had "unclear" or "high risk" of bias due to their unclear reporting. Many studies have unclear reporting of the study procedures that do not meet reporting standards. Future studies should provide complete, clear, and transparent information about how to create and present a research methodology and findings in accordance with CONSORT criteria and flowchart templates.

\section{Limitations}

This review's findings should be considered in light of several limitations. The studies we sampled differed considerably in their study participants' demographic variables (e.g., older, female, and White cancer patients), types of interventions, outcome measures, and timing of follow-ups. We could not conduct a meta-analysis that synthesizes their discrepant findings, which would have provided more rigorous evidence of the effects of uncertainty management interventions for cancer patients and their family caregivers. Additionally, our review only focused on interventions' effects on uncertainty outcomes. Future research should examine the effects of uncertainty management interventions on other outcomes in order to get a more comprehensive picture of the effect of interventions. We also focused only on peerreviewed published studies and may have missed relevant studies from the gray literature. Excluding unpublished studies likely increases the potential for biased findings; however, we included studies that reported non-significant results, thus mitigating the possibility of publication selection bias.

\section{Clinical and research implications}

Our review has numerous implications for future clinical practice and research. Providing uncertainty management interventions with multiple components at different phases of the cancer trajectory may significantly reduce uncertainty and facilitate adaptation among patients and family caregivers. There is strong evidentiary support that multi-component interventions yield effective outcomes. However, more research is needed to compare the discrete effects of different intervention components, modes of delivery, and formats on uncertainty management outcomes among cancer patients and their family caregivers. This research should also include study populations with diverse backgrounds (e.g., by age, gender, and/or race), and in particular seek to engage children and adolescents with cancer, males, and African Americans-all groups for whom few if any tailored uncertainty management interventions currently exist.

\section{Conclusion}

This systematic review underlines the promising potential of uncertainty management interventions - especially interventions involving multiple components including informational, emotional, appraisal, and instrumental support - to help cancer patients and their family caregivers manage illness uncertainty. Future research needs to employ a rigorous research methodology in order to test uncertainty management interventions among a diverse population and to ensure complete and accurate reporting of the research procedures and findings. 
Acknowledgments The authors are grateful to Elizabeth Moreton who helped to develop the search terms and identify search databases. We also would like to thank Dr. Jordan Wingate for his editorial assistance.

Code availability Not applicable

Funding Lixin Song's work was partially supported by R01NR016990 National Institute of Nursing Research (PI: Song), R21 CA212516 National Cancer Institute (PI: Song), and University Cancer Research Fund, UNC-Chapel Hill Lineberger Comprehensive Cancer Center
(LCCC). Guan's and Yousef's work was partially supported by University Cancer Research Fund, UNC-Chapel Hill LCCC (PI: Song).

Data availability All studies included in this review are publicly available.

\section{Compliance with ethical standards}

Conflict of interest The authors declare that they have no conflict of interest.

\section{Appendix}

Table 4 Cochrane Collaboration's criteria for assessing risk of bias

Domain Criteria

Sequence generation Allocation sequence was adequately generated.

Allocation
concealment
Blinding of
participants, and
personnel
Blinding outcome
assessment

Incomplete outcome data

Selective reporting

The study was free of apparent selective outcome reporting.

Deferential intervention use

Baseline imbalance Allocation of group assignment could not be foreseen before
randomization.

Knowledge of the allocated intervention by participant and personnel was adequately prevented during the study.

Knowledge of the allocated interventions by outcome assessors was adequately prevented during follow-up.

Incomplete outcome data were adequately addressed.
Reported outcome was among participants who similarly used interventions

Reported outcome was among balanced participants' characteristics across groups.
Random number table

Computer random number generator

Coin tossing

Card or envelope shuffling

Throwing dice

Used central allocation including telephone or web-based randomization

Used sequentially numbered, opaque, sealed envelopes

No blinding but unlikely that the outcome was influenced.

Blinding ensured for participants and key study personnel and unlikely to have been broken.

No blinding of outcome assessment, but the outcome is not influenced.

Blinding of outcome assessment ensured, and unlikely to have been broken.

No missing outcome data

Missing outcome data unlikely related to true outcome

Missing outcome data balanced across groups with similar reasons for missing data across groups

Plausible effect size among missing outcomes not enough to have impact on observed effect size

Missing data have been imputed using appropriate methods.

Study protocol available and all prespecified outcomes of interest reported

Study protocol is not available, but all expected prespecified outcomes reported.

All participants used intervention and complete all sessions.

Adjusting the statistical analysis according intervention use

Include all randomized participants

Used stratified randomization or minimization

Adjusting in the statistical analysis for baseline variables 
Open Access This article is licensed under a Creative Commons Attribution 4.0 International License, which permits use, sharing, adaptation, distribution and reproduction in any medium or format, as long as you give appropriate credit to the original author(s) and the source, provide a link to the Creative Commons licence, and indicate if changes were made. The images or other third party material in this article are included in the article's Creative Commons licence, unless indicated otherwise in a credit line to the material. If material is not included in the article's Creative Commons licence and your intended use is not permitted by statutory regulation or exceeds the permitted use, you will need to obtain permission directly from the copyright holder. To view a copy of this licence, visit http://creativecommons.org/licenses/by/4.0/.

\section{References}

1. Mishel MH (1988) Uncertainty in illness. J Nurs Scholarsh 20(4):225232

2. Garofalo JP, Choppala S, Hamann HA, Gjerde J (2009) Uncertainty during the transition from cancer patient to survivor. Cancer Nurs 32(4):E8-E14

3. Guan T, Guo, PR, Santacroce, SJ, Chen, DG, Song L (2020) A longitudinal perspective on illness uncertainty and its antecedents for patients with prostate cancer and their partners. Oncol Nurs Forum 47(6):721-731

4. Jabloo VG et al (2017) Antecedents and outcomes of uncertainty in older adults with cancer: a scoping review of the literature. Oncol Nurs Forum 44(4):E152-E167

5. Eisenberg SA, Kurita K, Taylor-Ford M, Agus DB, Gross ME, Meyerowitz BE (2015) Intolerance of uncertainty, cognitive complaints, and cancer-related distress in prostate cancer survivors. Psychooncology. 24(2):228-235

6. Germino BB, Mishel MH, Belyea M, Harris L, Ware A, Mohler J (1998) Uncertainty in prostate cancer: ethnic and family patterns. Cancer Pract 6(2):107-113

7. Santacroce SJ, Lee YL (2006) Uncertainty, posttraumatic stress, and health behavior in young adult childhood cancer survivors. Nurs Res 55(4):259-266

8. Wonghongkul T, Dechaprom N, Phumivichuvate L, Losawatkul S (2006) Uncertainty appraisal coping and quality of life in breast cancer survivors. Cancer Nurs 29(3):250-257

9. Sammarco A (2001) Perceived social support, uncertainty, and quality of life of younger breast cancer survivors. Cancer Nurs 24(3):212-219

10. Haegen MV, Etienne AM (2018) Intolerance of uncertainty in parents of childhood cancer survivors: a clinical profile analysis. J Psychosoc Oncol 36(6):717-733

11. Tackett AP, Cushing CC, Suorsa KI, Mullins AJ, Gamwell KL, Mayes S, McNall-Knapp R, Chaney JM, Mullins LL (2016) Illness uncertainty, global psychological distress, and posttraumatic stress in pediatric cancer: a preliminary examination using a path analysis approach. J Pediatr Psychol 41(3):309-318

12. Guan T, Santacroce SJ, Chen DG, Song L (2020) Illness uncertainty, coping, and quality of life among patients with prostate cancer. Psychooncology. 29(6):1019-1025

13. Dawson G, Madsen LT, Dains JE (2016) Interventions to manage uncertainty and fear of recurrence in female breast cancer survivors: a review of the literature. Clin J Oncol Nurs 20(6):E155-E161

14. Gunter MD, Duke G (2018) Reducing uncertainty in families dealing with childhood cancers: an integrative literature review. Pediatr Nurs 44(1):21-37
15. Zhang Y, Kwekkeboom K, Kim KS, Loring S, Wieben AM (2020) Systematic review and meta-analysis of psychosocial uncertainty management interventions. Nurs Res 69(1):3-12

16. Tritter JQ, Calnan M (2002) Cancer as a chronic illness? Reconsidering categorization and exploring experience. Eur $\mathrm{J}$ Cancer Care 11(3):161-165

17. Panjwani AA, Marín-Chollom AM, Pervil IZ, Erblich J, Rubin LR, Schuster MW, Revenson TA (2019) Illness uncertainties tied to developmental tasks among young adult survivors of hematologic cancers. J Adolesc and Young Adult Oncol 8(2):149-156

18. Fortier MA, Batista ML, Wahi A, Kain A, Strom S, Sender LS (2013) Illness uncertainty and quality of life in children with cancer. J Pediatr Hematol Oncol 35(5):366-370

19. Moher D, Liberati A, Tetzlaff J, Altman DG, The PRISMA Group (2009) Preferred Reporting Items for Systematic Reviews and Meta-Analyses: the PRISMA statement. PLoS Med 6(7):e1000097

20. Liberati A, Altman DG, Tetzlaff J, Mulrow C, Gøtzsche PC, Ioannidis JPA, Clarke M, Devereaux PJ, Kleijnen J, Moher D (2009) The PRISMA statement for reporting systematic reviews and meta-analyses of studies that evaluate health care interventions: explanation and elaboration. PLoS Med 6(7):e1000100

21. Cochrane Community [Internet]. Author; c2020. About covidence.; 2018 [cited 2020 June 22]. Available from: https://community. cochrane.org/help/tools-and-software/covidence/about-covidence

22. Higgins JP et al (2011) The Cochrane Collaboration's tool for assessing risk of bias in randomised trials. BMJ. 343:d5928

23. House JS, Umberson D, Landis KR (1988) Structures and processes of social support. Annu Rev Soc 14(1):293-318

24. Mori M, Fujimori M, Vliet LM, Yamaguchi T, Shimizu C, Kinoshita T, Morishita-Kawahara M, Inoue A, Inoguchi H, Matsuoka Y, Bruera E, Morita T, Uchitomi Y (2019) Explicit prognostic disclosure to Asian women with breast cancer: a randomized, scripted video-vignette study (J-SUPPORT1601). Cancer. 125(19):3320-3329

25. Chow KM, Chan CWH, Chan JCY, Choi KKC, Siu KY (2014) A feasibility study of a psychoeducational intervention program for gynecological cancer patients. Eur J Oncol Nurs 18(4):385-392

26. Christman NJ, Cain LB (2004) The effects of concrete objective information and relaxation on maintaining usual activity during radiation therapy. Oncol Nurs Forum 31(2):E39-E45

27. Germino BB, Mishel MH, Crandell J, Porter L, Blyler D, Jenerette C, Gil KM (2013) Outcomes of an uncertainty management intervention in younger African American and Caucasian breast cancer survivors. Oncol Nurs Forum 40(1):82-92

28. Tomei C, Lebel S, Maheu C, Lefebvre M, Harris C (2018) Examining the preliminary efficacy of an intervention for fear of cancer recurrence in female cancer survivors: a randomized controlled clinical trial pilot study. Support Care Cancer 26(8):2751-2762

29. Kazer MW, Bailey DE, Sanda M, Colberg J, Kelly WK (2011) An internet intervention for management of uncertainty during active surveillance for prostate cancer. Oncol Nurs Forum 38:561-568

30. Northouse LL, Mood DW, Schafenacker A, Kalemkerian G, Zalupski M, LoRusso P, Hayes DF, Hussain M, Ruckdeschel J, Fendrick AM, Trask PC, Ronis DL, Kershaw T (2013) Randomized clinical trial of a brief and extensive dyadic intervention for advanced cancer patients and their family caregivers. Psychooncology. 22(3):555-563

31. McCaughan E, Curran C, Northouse L, Parahoo K (2018) Evaluating a psychosocial intervention for men with prostate cancer and their partners: outcomes and lessons learned from a randomized controlled trial. Appl Nurs Res 40:143-151

32. Northouse L, Kershaw T, Mood D, Schafenacker A (2005) Effects of a family intervention on the quality of life of women with recurrent breast cancer and their family caregivers. Psychooncology. 14(6):478-491

33. Northouse LL, Mood DW, Schafenacker A, Montie JE, Sandler HM, Forman JD, Hussain M, Pienta KJ, Smith DC, Kershaw T 
(2007) Randomized clinical trial of a family intervention for prostate cancer patients and their spouses. Cancer. 110(12):2809-2818

34. Hendricks-Ferguson VL, Pradhan K, Shih CS, Gauvain KM, Kane JR, Liu J, Haase JE (2017) Pilot evaluation of a palliative and endof-life communication intervention for parents of children with a brain tumor. J Pediatr Oncol Nurs 34(3):203-213

35. Ye ZJ, Liang MZ, Qiu HZ, Liu ML, Hu GY, Zhu YF, Zeng Z, Zhao JJ, Quan XM (2016) Effect of a multidiscipline mentor-based program, Be Resilient to Breast Cancer (BRBC), on female breast cancer survivors in mainland China: a randomized, controlled, theoretically-derived intervention trial. Breast Cancer Res Treat 158(3):509-522

36. Wang J, Howell D, Shen N, Geng Z, Wu F, Shen M, Zhang X, Xie A, Wang L, Yuan C (2018) mHealth supportive care intervention for parents of children with acute lymphoblastic leukemia: quasi-experimental pre- and postdesign study. JMIR Mhealth Uhealth 6(11):e195

37. Lebel S, Maheu C, Lefebvre M, Secord S, Courbasson C, Singh M, Jolicoeur L, Benea A, Harris C, Fung MFK, Rosberger Z, Catton P (2014) Addressing fear of cancer recurrence among women with cancer: a feasibility and preliminary outcome study. J Cancer Surviv 8(3):485496

38. Mishel MH, Belyea M, Germino BB, Stewart JL, Bailey DE, Robertson C, Mohler J (2002) Helping patients with localized prostate carcinoma manage uncertainty and treatment side effects: nurse-delivered psychoeducational intervention over the telephone. Cancer. 94(6): 1854-1866

39. Mishel MH, Germino BB, Lin L, Pruthi RS, Wallen EM, Crandell J, Blyler D (2009) Managing uncertainty about treatment decision making in early stage prostate cancer: a randomized clinical trial. Patient Educ Couns 77(3):349-359

40. Ha XTN, Thanasilp S, Thato R (2019) The effect of uncertainty management program on quality of life among Vietnamese women at 3 weeks postmastectomy. Cancer Nurs 42(4):261-270

41. Ritz LJ, Nissen MJ, Swenson KK, Farrell JB, Sperduto PW, Sladek ML, Lally RM, Schroeder LM (2000) Effects of advanced nursing care on quality of life and cost outcomes of women diagnosed with breast cancer. Oncol Nurs Forum 27(6):923-932

42. Schulman-Green D, Jeon S (2017) Managing cancer care: a psychoeducational intervention to improve knowledge of care options and breast cancer self-management. Psychooncology. 26(2):173-181

43. Wells-Di Gregorio SM et al (2019) Pilot randomized controlled trial of a symptom cluster intervention in advanced cancer. Psychooncology. 28(1):76-84

44. Victorson D, Hankin V, Burns J, Weiland R, Maletich C, Sufrin N, Schuette S, Gutierrez B, Brendler C (2017) Feasibility, acceptability and preliminary psychological benefits of mindfulness meditation training in a sample of men diagnosed with prostate cancer on active surveillance: results from a randomized controlled pilot trial. Psychooncology. 26(8):1155-1163
45. Dharmarajan KV, Walters CB, Levin TT, Milazzo CA, Monether C, Rawlins-Duell R, Tickoo R, Spratt DE, Lovie S, Giannantoni-Ibelli G, McCormick B (2019) A video decision aid improves informed decision making in patients with advanced cancer considering palliative radiation therapy. J Pain Symptom Manag 58(6):1048-1055

46. El-Jawahri A et al (2010) Use of video to facilitate end-of-life discussions with patients with cancer: a randomized controlled trial. J Clin Oncol 28(2):305-310

47. Liu LN, Li CY, Tang ST, Huang CS, Chiou AF (2006) Role of continuing supportive cares in increasing social support and reducing perceived uncertainty among women with newly diagnosed breast cancer in Taiwan. Cancer Nurs 29(4):273-282

48. Sussman J, Bainbridge D, Whelan TJ, Brazil K, Parpia S, Wiernikowski J, Schiff S, Rodin G, Sergeant M, Howell D (2018) Evaluation of a specialized oncology nursing supportive care intervention in newly diagnosed breast and colorectal cancer patients following surgery: a cluster randomized trial. Support Care Cancer 26(5):1533-1541

49. McCorkle R, Dowd M, Ercolano E, Schulman-Green D, Williams AL, Siefert ML, Steiner J, Schwartz P (2009) Effects of a nursing intervention on quality of life outcomes in post-surgical women with gynecological cancers. Psychooncology. 18(1):62-70

50. Fridriksdottir N, Gunnarsdottir S, Zoëga S, Ingadottir B, Hafsteinsdottir EJG (2018) Effects of web-based interventions on cancer patients' symptoms: review of randomized trials. Support Care Cancer 26(2):337-351

51. Northouse LL, Rosset T, Phillips L, Mood D, Schafenacker A, Kershaw T (2006) Research with families facing cancer: the challenges of accrual and retention. Res Nurs Health 29(3):199-211

52. Kent EE, Rowland JH, Northouse L, Litzelman K, Chou WYS, Shelburne N, Timura C, O'Mara A, Huss K (2016) Caring for caregivers and patients: research and clinical priorities for informal cancer caregiving. Cancer. 122(13):1987-1995

53. Northouse L, Williams AL, Given B, McCorkle R (2012) Psychosocial care for family caregivers of patients with cancer. J Clin Oncol 30(11):1227-1234

54. Northouse LL, Katapodi MC, Schafenacker AM, Weiss D (2012) The impact of caregiving on the psychological well-being of family caregivers and cancer patients. Semin Oncol Nurs 28(4):236-245

55. Stewart JL, Mishel MH, Lynn MR, Terhorst L (2010) Test of a conceptual model of uncertainty in children and adolescents with cancer. Res Nurs Health. 33(3):179-191

56. Hillen MA, Gutheil CM, Smets EMA, Hansen M, Kungel TM, Strout TD, Han PKJ (2017) The evolution of uncertainty in second opinions about prostate cancer treatment. Health Expect 20(6):1264-1274

Publisher's note Springer Nature remains neutral with regard to jurisdictional claims in published maps and institutional affiliations. 